\title{
Structures on Q-Fuzzy Left N-Subgroups of Near Rings under Triangular Norms
}

\author{
S.Subramanian \\ Assistant Professor \\ Department of Mathematics \\ Saranathan College of Engineering \\ Trichy-620 012 \\ Tamil Nadu, India
}

\author{
Dr.B.Chellappa \\ Associate Professor \\ Department of Mathematics \\ Alagappa Government Arts College \\ Karaikudi-630 003 \\ Tamil Nadu, India
}

\begin{abstract}
In this paper, we introduce the notion of Q-Fuzzification of left $\mathrm{N}$-Subgroups in a near ring and investigate some related properties, characterization of Q-Fuzzy left NSubgroups with respect to a triangular norm are given.
\end{abstract}

Ams subject classification (2000: 03F055, 03E72, 20N25 Keywords: Q-Fuzzy set, Q-Fuzzy left N-subgroup, sub near rings, Homomotphisms, Sup property, t-norm.

\section{SECTION-1 INTRODUCTION}

The theory of Fuzzy sets which was introduced by Zedah [7] is applied to many mathematical branches. Abou-Zoid [1] , introduced the notion of a fuzzy sub near ring and studied Fuzzy ideals of near ring. This concept discussed by many researchers among Cho, Davvaz, Dudek, Jun, Kim [2], [3], [4]. In [5], considered the intuitionistic Fuzzification of a right crisp left R.Subgroup in a near ring. A.Solairaju and R.Nagarajan [6] introduced a notion of QFuzzy Groups. Also cho.et.al in [4] the notion of normal intuitionistic Fuzzy R-Sub group in a near ring is introduced and related are investigated. The notion of intuitionistic Q-Fuzzy semi primality in a semi group is given by Kim [3]. In this paper, we introduce the notion of Q-Fuzzification of left N-Subgroups in a near ring and investigate some related properties. Characterization of QFuzzy left N-Subgroups are given.

\subsubsection{Section-2 PRELIMINARIES:}

Definition 2.1 : A non empty set with two binary operations ' + ' and '?' is called a near ring if it satisfies the following axioms;

$$
\begin{array}{ll}
\text { (i) } & (S,+) \text { is a group. } \\
\text { (ii) } & (S, .) \text { is a semigroup. } \\
\text { (iii) } & \text { x. }(y+z)=x \cdot y+x . z \\
& \text { for all } x, y, z \in S .
\end{array}
$$

Precisely speaking it is a left near ring. Because it satisfies the left distribution Low. As N-Subgroup of a near ring ' $S$ ' is a subset ' $H$ ' of ' $S$ ' such that
(i)
(ii)
$(\mathrm{H},+)$ is a Sub group of $(\mathrm{S},+)$
(iii) $\mathrm{HS} \subset \mathrm{H}$.

If ' $\mathrm{H}$ ' satisfies (i) and (ii) then it is called left $\mathrm{N}=$ Subgroup of ' $\mathrm{S}$ ' and if ' $\mathrm{N}$ ' satisfies (i) and (iii) then it is called right $\mathrm{N}$-Subgroup of $\mathrm{S}$.

A map $\mathrm{f}: \mathrm{R} \rightarrow \mathrm{S}$ is called homomorphism if $\mathrm{f}(\mathrm{x}+\mathrm{y})=\mathrm{f}(\mathrm{x})+$ $f(y)$ for all $x, y$ in $S$.

\section{Definition 2.2 :}

Let ' $\mathrm{S}$ ' be a near ring. A Fuzzy set $\mathrm{I}$ in ' $\mathrm{S}$ ' is called Q-Fuzzy sub near ring in $\mathrm{S}$ if

(i) $\mu(x-y, a) \geq \min \{\mu(x, a), \mu(y, a)\}$

(ii) $\mu(\mathrm{xy}, \mathrm{a}) \geq \min \{\mu(\mathrm{x}, \mathrm{a}), \mu(\mathrm{y}, \mathrm{a})\}$ for all $\mathrm{x}, \mathrm{y}$ in $\mathrm{S}$.

\section{Definition 2.3 :}

A mapping $\mu: X \rightarrow[0,1]$, where $X$ is an arbitrary non empty set and is called Fuzzy Set in $\mathrm{X}$.

\section{Definition 2.4 :}

Let $\mathrm{Q}$ and $\mathrm{N}$ a set and group respectively. A mapping $\mu: \mathrm{N}$ $\mathrm{X} \mathrm{Q} \rightarrow[0,1]$ is called Q-Fuzzy set in $\mathrm{N}$.

\section{Definition 2.5 : ( T-norm )}

A triangular norm is a function $\mathrm{T}:[0,1] \mathrm{X}[0,1] \rightarrow[0,1]$ that satisfies the following conditions for all $\mathrm{x}, \mathrm{y}, \mathrm{z}$ in $[0,1]$.

$$
\begin{array}{ll}
\left(\mathrm{T}_{1}\right) & \mathrm{T}(\mathrm{x}, 1)=\mathrm{x} \\
\left(\mathrm{T}_{2}\right) & \mathrm{T}(\mathrm{x}, \mathrm{y})=\mathrm{T}(\mathrm{y}, \mathrm{x}) \\
\left(\mathrm{T}_{3}\right) & \mathrm{T}[\mathrm{x}, \mathrm{T}(\mathrm{y}, \mathrm{z})]=\mathrm{T}(\mathrm{T}(\mathrm{x}, \mathrm{y}), \mathrm{z}) \\
\left(\mathrm{T}_{4}\right) & \mathrm{T}(\mathrm{x}, \mathrm{y}) \leq \mathrm{T}(\mathrm{x}, \mathrm{z}) \text { when } \mathrm{y} \leq \mathrm{z} .
\end{array}
$$

Definition 2.6 :

A Q-Fuzzy Set ' $\mu$ ' is called a Q-Fuzzy left N-Sub group of $S$ over $Q$ if $\mu$ satisfies
(i)
$\mu(\mathrm{n}(\mathrm{x}-\mathrm{y}, \mathrm{q}) \geq \mathrm{T}\{\mu(\mathrm{x}, \mathrm{q}), \mu(\mathrm{y}, \mathrm{q})\}$
(ii)

$$
\begin{aligned}
& \mu(n x, q) \geq\{\mu(x, q)\} \\
& \text { for all } x, y, n \in S \text { and } q \in Q \text {. }
\end{aligned}
$$

\subsubsection{Section.3 \\ Properties of Q-Fuzzy left $N$-Subgroups Preposition 3.1 :}

Let ' $\mathrm{T}$ ' be a t-norm then every imaginable Q-Fuzzy left NSubgroup ' $\mu$ ' of a near ring ' $S$ ' is a Fuzzy left N-Subgroup of S. 
Proof: Assume' $\mu$ ' is imaginable Q-Fuzzy left NSubgroup of $S$, then we have $\mu(\mathrm{n}(\mathrm{x}-\mathrm{y}, \mathrm{q}) \geq \mathrm{T}\{\mu(\mathrm{x}, \mathrm{q}), \mu(\mathrm{y}, \mathrm{q})\}$ and $\mu(\mathrm{nx}, \mathrm{q}) \geq\{\mu(\mathrm{x}, \mathrm{q})\}$ for all $x, y$ in $S$.

Since ' $\mu$ ' is imaginable, We have

$\operatorname{Min}\{\mu(\mathrm{x}, \mathrm{q}), \mu(\mathrm{y}, \mathrm{q})\}=\mathrm{T}[\min \{\mu(\mathrm{x}, \mathrm{q})$, $\mu(y, q)\}, \min \{\mu(x, q), \mu(y, q)\}$

$$
\begin{aligned}
& \leq \mathrm{T}\{\mu(\mathrm{x}, \mathrm{q}), \mu(\mathrm{y}, \mathrm{q})\} \\
& \leq \min \{\mu(\mathrm{x}, \mathrm{q}), \mu(\mathrm{y}, \mathrm{q})\} \\
& \text { and so }
\end{aligned}
$$

$\mathrm{T}\{\mu(\mathrm{x}, \mathrm{q}), \mu(\mathrm{y}, \mathrm{q})\}=\min \{\mu(\mathrm{x}, \mathrm{q}), \mu(\mathrm{y}, \mathrm{q})\}$

It follows that $\mu(\mathrm{n}(\mathrm{x}-\mathrm{y}), \mathrm{q}) \geq \mathrm{T}\{\mu(\mathrm{x}, \mathrm{q}), \mu(\mathrm{y}, \mathrm{q})\}$

$=\min \{\mu(x, q), \mu(y, q)\}$ for all $x, y \in S$.

Hence ' $\mu$ ' is a Fuzzy left N-Subgroup of $S$.

\section{Preposition 3.2 :}

If ' $\mu$ ' is Q-Fuzzy left N-Subgroups of a near ring 'S' and Q is a endomorphism of $\mathrm{S}$, then $\mu_{(\mathrm{Q})}$ is a Q-Fuzzy left $\mathrm{N}$ Subgroup of S.

Proof : For any $x, y \in S$, We have

(i) $\mu_{[Q]}(n(x-y, q)=\mu(Q n(x-y, q)$

$$
\begin{aligned}
& =\mu\{(\mathrm{Q}(\mathrm{x}, \mathrm{q}), \mathrm{Q}(\mathrm{y}, \mathrm{q})\} \\
& \geq \mathrm{T}\{\mu(\mathrm{Q}(\mathrm{x}, \mathrm{q}), \mu(\mathrm{Q}(\mathrm{y}, \mathrm{q})\} \\
& =\mathrm{T}\left\{\mu_{[\mathrm{Q}]}\left((\mathrm{x}, \mathrm{q}), \mu_{[\mathrm{Q}]}(\mathrm{y}, \mathrm{q})\right\}\right.
\end{aligned}
$$

(ii) $\mu_{[\mathrm{Q}]}(\mathrm{nx}, \mathrm{q})=\mu(\mathrm{Q}(\mathrm{nx}, \mathrm{q})]$

$$
\geq \mu(\mathrm{Q}(\mathrm{x}, \mathrm{q})]
$$$$
\left.\geq \mu_{[\mathrm{Q}]}(\mathrm{x}, \mathrm{q})\right]
$$

Hence $\mu_{(\mathrm{Q}]}(\mathrm{x}, \mathrm{q})$ is Q-Fuzzy left N-Subgroup of S.

\section{Preposition 3.3 :}

An onto homomorphism of a Q-Fuzzy left N-subgroup of near ring ' $\mathrm{S}$ ' is G-Fuzzy left $\mathrm{N}$ Subgroup.

Proof: Let $\mathrm{f}: \mathrm{S} \rightarrow \mathrm{S}^{1}$ be an onto homomorphism of near rings and ' $\square$ ' be a Q-Fuzzy left N- Subgroup of $\mathrm{S}^{1}$ and ' $\mu$ ' be the pre image of ' $\square$ ' under $f$ then We have

$$
\text { (i) } \begin{aligned}
\mu((\mathrm{n}(\mathrm{x}-\mathrm{y}), \mathrm{q})] & =\square(\mathrm{f}(\mathrm{n}(\mathrm{x}-\mathrm{y}), \mathrm{q}) \\
& =\square(\mathrm{f}(\mathrm{x}, \mathrm{q}), \mathrm{f}(\mathrm{y}, \mathrm{q})\} \\
& \geq \mathrm{T}\{\mu(\mathrm{f}(\mathrm{x}, \mathrm{q}), \mu \\
& \geq \mathrm{T}\{(\mathrm{f}(\mathrm{x}, \mathrm{q}),(\mathrm{f}(\mathrm{y}, \mathrm{q}) \\
\text { (ii) } \mu(\mathrm{nx}, \mathrm{q})= & \square(\mathrm{f}(\mathrm{nx}, \mathrm{q})\} \\
\geq & \square(\mathrm{f}(\mathrm{x}, \mathrm{q})\} \\
\geq & \mu(\mathrm{x}, \mathrm{q})
\end{aligned}
$$$$
=\square(\mathrm{f}(\mathrm{x}, \mathrm{q}), \mathrm{f}(\mathrm{y}, \mathrm{q})\}
$$$$
\geq \mathrm{T}\{\mu(\mathrm{f}(\mathrm{x}, \mathrm{q}), \mu(\mathrm{f}(\mathrm{y}, \mathrm{q})\}
$$$$
\geq \mathrm{T}\{(\mathrm{f}(\mathrm{x}, \mathrm{q}),(\mathrm{f}(\mathrm{y}, \mathrm{q})\}
$$

Preposition 3.4 : An onto homomorphic image of a QFuzzy left N-Subgroup with the supremum property is a QFuzzy left N-subgroup.

Proof: Let f : $\mathrm{S} \rightarrow \mathrm{S}^{1}$ be an onto homomorphic of near rings and let ' $\mu$ ' be a supremum property of Q-Fuzzy $\mathrm{N}$ - Subgroup of $\mathrm{S}^{1}$.

Let $\mathrm{x}^{1}, \mathrm{y}^{1} \in \mathrm{S}^{1}$ and $\mathrm{x}_{\mathrm{o}} \in \mathrm{f}^{-1}\left(\mathrm{x}^{1}\right), \mathrm{y}_{\mathrm{o}} \in \mathrm{f}^{-1}\left(\mathrm{y}^{1}\right)$ be such that

$$
\mu(x o, q)=\operatorname{Sup}_{(h, a) \in f-1\left(x^{1}\right)} \mu(h, q
$$

$$
\mu\left(y_{0} q\right)=\operatorname{Sup}_{(h, q) \in f-1\left(y^{1}\right)}\{\mu(h, q)\} \text { respectively. }
$$

Then we can deduce that

$$
\begin{aligned}
& \text { (i) } \mu^{\mathrm{f}}\left(\mathrm{n}\left(\mathrm{x}^{1}-\mathrm{y}^{1}\right), \mathrm{q}\right)=\operatorname{Sup} \mu(\mathrm{z}, \mathrm{q}) \\
& \begin{array}{l}
(\mathrm{z}, \mathrm{a}) \in \mathrm{f}-1\left(\mathrm{n}\left(\mathrm{x}^{1}-\mathrm{y}^{1}\right), \mathrm{q}\right) \\
>\mathrm{T}\left\{\mu\left(\mathrm{x}_{0}, \mathrm{q}\right), \mu\left(\mathrm{y}_{0}, \mathrm{q}\right)\right\}
\end{array} \\
& \geq \mathrm{T}\left\{\operatorname{Sup}\left(\mathrm{x}_{\mathrm{o}}, \mathrm{q}\right), \operatorname{Sup}\left(\mathrm{y}_{\mathrm{o}} \mathrm{q}\right)\right\} \\
& (h, a) \in f^{\prime}\left(x^{\prime}\right) \quad(h, a) \in f^{\prime}\left(y^{\prime}\right) \\
& =\mathrm{T}\left\{\mu^{\mathrm{t}}\left(\mathrm{x}^{\prime}, \mathrm{q}\right), \mu^{\mathrm{t}}\left(\mathrm{y}^{\prime}, \mathrm{q}\right)\right\}
\end{aligned}
$$

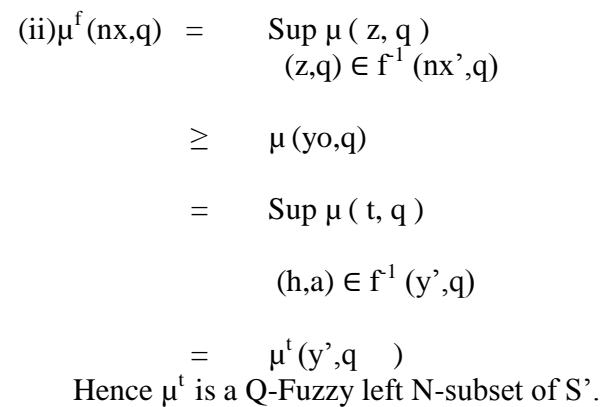

\section{Preposition 3.5:}

Let ' $\mathrm{T}$ ' be a continuous t-norm and let ' $\mathrm{f}$ ' be a homomorphism on a near ring ' $S$ ' if ' $\mu$ ' is Q-Fuzzy left $\mathrm{N}$-Subgroup of $\mathrm{S}$, then $\mu^{\mathrm{f}}$ is a Q-Fuzzy left N-Subgroup of $\mathrm{f}(\mathrm{S})$.

Proof : Let $A_{1}=f^{-1}\left(y_{1}, q\right)$, and $A_{2}=f^{-1}\left(y_{2}, q\right)$ and $A_{12}=f^{-1}\left(n\left(y_{1}-y_{2}, q\right)\right.$ where $y_{1}, y_{2} \in f(S), q \in Q$.

Consider the set $A_{1}-A_{2}=\left\{x \in S /(x, q)=\left(a_{1}-q\right)-\left(a_{2}-q\right)\right\}$ for some $\left(a_{1}, q\right) \in A_{1}$ and $\left(a_{2}, q\right) \in A_{2}$ If $(x, q) \in A_{1}-A_{2}$, then $(x, q)=\left(x_{1}-q\right)-\left(x_{2}-q\right)$ for some $\left(x_{1}-q\right) \in A_{1}$ and $\left(x_{2}, q\right) \in A_{2}$ so that We have

$$
\begin{aligned}
& f(x, q) \quad=f\left(x_{1}, q\right)-f\left(x_{2}, q\right) \\
& =\mathrm{y}_{1}-\mathrm{y}_{2} \\
& \therefore(\mathrm{x}, \mathrm{q}) \in \mathrm{f}^{-1}\left[\left(\mathrm{y}_{1}-\mathrm{q}\right)-\left(\mathrm{y}_{2}-\mathrm{q}\right]\right)=\mathrm{f}^{-1}\left(\mathrm{n}\left(\mathrm{y}_{1}-\mathrm{y}_{2}\right), \mathrm{q}\right) \\
& =\mathrm{A}_{12} \text { Thus } \\
& \mathrm{A}_{1}-\mathrm{A}_{2} \subset \mathrm{A}_{12} \\
& \text { It follows that } \\
& \mu^{\mathrm{f}}\left[\mathrm{n}\left(\mathrm{y}_{1}-\mathrm{y}_{2}\right), \mathrm{q}\right)=\operatorname{Sup}\{\mu(\mathrm{x}, \mathrm{q}) / \\
& \left.(x, q) \in f^{-1}\left(y_{1}-q\right),\left(y_{2}-q\right)\right\} \\
& =\operatorname{Sup}\left\{\mu(\mathrm{x}, \mathrm{q}) /(\mathrm{x}, \mathrm{q}) \in \mathrm{A}_{12}\right\} \\
& \geq \operatorname{Sup}\left\{\mu(\mathrm{x}, \mathrm{q}) /(\mathrm{x}, \mathrm{q}) \in \mathrm{A}_{1}-\mathrm{A}_{2}\right\} \\
& \geq \operatorname{Sup}\left\{\mu\left(\mathrm{x}_{1}-\mathrm{q}\right)-\left(\mathrm{x}_{2}-\mathrm{q}\right) /\right. \\
& \left.\left(\mathrm{x}_{1}, \mathrm{q}\right) \in \mathrm{A}_{1} \text { and }\left(\mathrm{x}_{2}, \mathrm{q}\right) \in \mathrm{A}_{2}\right\}
\end{aligned}
$$

Since $\mathrm{T}$ is continuous, For every $\in>0$,

$$
\text { We see that If }
$$

$\left.\operatorname{Sup}\left\{\mu\left(\mathrm{x}_{1}, \mathrm{q}\right) /\left(\mathrm{x}_{1}, \mathrm{q}\right) \in \mathrm{A}_{1}\right\}-\left(\mathrm{x}_{1}{ }^{*}, \mathrm{q}\right) \in \mathrm{A}_{2}\right\} \leq \delta$ and

$\left.\operatorname{Sup}\left\{\mu\left(x_{2}, q\right) /\left(x_{2}, q\right) \in A_{2}\right\}-\left(x_{2}{ }^{*}, q\right) \in A_{2}\right\} \leq \delta$

$\mathrm{T}\left\{\operatorname{Sup}\left\{\mu\left(\mathrm{x}_{1}, \mathrm{q}\right) /\left(\mathrm{x}_{1}, \mathrm{q}\right) \in \mathrm{A}_{1}\right\}\right.$,

$\operatorname{Sup}\left\{\mu\left(x_{2}, q\right) /\left(x_{2}, q\right) \in A_{2}\right\}-T\left\{\left(x_{1}{ }^{*}, q\right)\right.$,

$$
\left.\left(\mathrm{x}_{2}{ }^{*}, \mathrm{q}\right)\right\} \leq \epsilon
$$

Choose $\left(a_{1}, q\right) \in A_{1}$ and $\left(a_{2}, q\right) \in A_{2}$ such that Sup \{ $\left.\mu\left(x_{1}, q\right) /\left(x_{1}, q\right) \in A_{1}\right\}-\mu\left(a_{1}, q\right) \leq \delta$ then we have $\mathrm{T}\left\{\operatorname{Sup}\left\{\mu\left(\mathrm{x}_{1}, \mathrm{q}\right) /\left(\mathrm{x}_{1}, \mathrm{q}\right) \in \mathrm{A}_{1}\right\}\right.$, $\operatorname{Sup}\left\{\mu\left(x_{2}, q\right) /\left(x_{2}, q\right) \in A_{2}\right\}$ 
Consequently We have

$$
-\mathrm{T}\left\{\mu\left(\mathrm{a}_{1}, \mathrm{q}\right)-\mu\left(\mathrm{a}_{2}, \mathrm{q}\right)\right\} \leq \epsilon
$$

$$
\begin{aligned}
& \mu^{\mathrm{t}}\left(\mathrm{n}\left(\mathrm{y}_{1}-\mathrm{y}_{2}, \mathrm{q}\right)\right. \geq \operatorname{Sup}\left\{\mathrm { T } \left(\mu\left(\mathrm{x}_{1}, \mathrm{q}\right), \mu\left(\mathrm{x}_{2}, \mathrm{q}\right) /\right.\right. \\
&\left.\left(\mathrm{x}_{1}, \mathrm{q}\right) \in \mathrm{A}_{1} \text { and }\left(\mathrm{x}_{2}, \mathrm{q}\right) \in \mathrm{A}_{2}\right\} \\
& \geq \mathrm{T}\left\{\operatorname { s u p } \left\{\mu\left(\mathrm{x}_{1}, \mathrm{q}\right) /\left(\mathrm{x}_{1}, \mathrm{q}\right) \in \mathrm{A}_{1} . \operatorname{Sup}\left\{\mu \left(\mathrm{x}_{2},\right.\right.\right.\right.
\end{aligned}
$$$$
\text { q) } \left./\left(x_{2}, q\right) \in A_{2}\right\}
$$

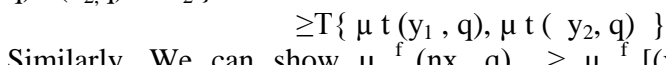

Similarly, We can show $\mu^{\mathrm{f}}(\mathrm{nx}, \mathrm{q}) \geq \mu^{\mathrm{f}}[(\mathrm{x}, \mathrm{q})$. Hence $\mu^{\mathrm{f}}$ is a Q-Fuzzy left N-Subgroup of $\mathrm{f}(\mathrm{S})$.

\section{Preposition 3.6}

Let ' $\mu$ ' be a Q-Fuzzy left N-Subgroup of S. then the QFuzzy subset $\langle\mu\rangle$ is Q-Fuzzy left N-Subgroup of $\mathrm{S}$ generated by ' $\mu$ ' more over $\langle\mu>$ is the smallest Q-Fuzzy left N-Subgroup containing it.

Proof: Let $\mathrm{x}, \mathrm{y} \in \mathrm{N}$ and let $\mu(\mathrm{x}, \mathrm{q})=\mathrm{t}_{1}$,

Let it $\begin{array}{lll}\mu(\mathrm{y}, \mathrm{q})=\mathrm{t}{ }_{\text {possible }} & \mathrm{t}\end{array} \quad$ and $\quad \begin{array}{rr}\mu(\mathrm{n}(\mathrm{x}-\mathrm{y}, \mathrm{q})=\mathrm{t} \\ = & \langle\mu\rangle(\mathrm{n}(\mathrm{x}-\mathrm{y}), \mathrm{q})\end{array}$

$$
\begin{gathered}
\leq \mathrm{T}\{<\mu>(\mathrm{x}, \mathrm{q}),<\mu>(\mathrm{n}(\mathrm{y}, \mathrm{q})\} \\
=\mathrm{T}\left\{\mathrm{t}_{1}, \mathrm{t}_{2}\right\}=\mathrm{t}_{1} \text { (say) }
\end{gathered}
$$

Then $\mathrm{t}_{1}=\langle\mu\rangle(\mathrm{x}, \mathrm{a})=\operatorname{Sup}\left\{\mathrm{k} / \mathrm{x} \in\left\langle\mu_{\mathrm{k}}\right\rangle\right\} \geq \mathrm{t}$

Therefore there exist $k_{1}$, such that $x \in\left\langle\mu_{\mathrm{k} 1}\right\rangle$. Also

$\mathrm{t}_{2}=\left\langle\mu>(\mathrm{y}, \mathrm{q})=\operatorname{Sup}\left\{\mathrm{k} / \mathrm{y} \in\left\langle\mu_{\mathrm{k}}>\right\} \geq \mathrm{t}\right.\right.$,

Therefore there exist $\left.\mathrm{k}_{2}\right\rangle \mathrm{t}$ such that $\mathrm{y} \in\left\langle\mu_{\mathrm{k}}\right\rangle$

without loss of generality, We may assume that $\mathrm{k}_{1}, \mathrm{k}_{2}$ so that $\left\langle\mu \mathrm{k}_{1}\right\rangle \subset\left\langle\mu \mathrm{k}_{2}\right\rangle$. Then $\mathrm{x}, \mathrm{y} \in\left\langle\mu_{\mathrm{k}}\right\rangle$ that is $\mathrm{n}(\mathrm{x}-\mathrm{y})$ which is a contradiction since $k_{2}>t$ Therefore $t \geq t_{1}$

Consequently ,

$\mu(n(x-y, q) \geq T\{<\mu>(x, q),<\mu>((y, q)\}--------1$

Now let, if possible,

$$
\mathrm{t}_{3}=\{<\mu>(\mathrm{nx}, \mathrm{q}) \leq<\mu>(\mathrm{x}, \mathrm{q})\}=\mathrm{t}_{1}
$$

Then $\mathrm{t}_{1}=\langle\mu\rangle(\mathrm{x}, \mathrm{q})=\operatorname{Sup}\left\{\mathrm{k} / \mathrm{x} \in\left\langle\mu_{\mathrm{k}}\right\rangle\right\}>\mathrm{t}_{3}$

Therefore there exists k such that $x \in\left\langle\mu_{k}\right\rangle$ and $\left.\left.t_{1}\right\rangle k\right\rangle t_{3}$ so that $n x \in\left\langle\mu_{k}\right\rangle \subset\left\langle\mu_{t}\right\rangle$ which is a contradiction.

Hence $\mathrm{t}_{3}=\left\{\left\langle\mu>(\mathrm{nx}, \mathrm{q}) \geq\left\{\left\langle\mu>(\mathrm{x}, \mathrm{q})=\mathrm{t}_{2}-\mathbf{2}\right.\right.\right.\right.$

Consequently Conditions (1) 2yield that $\langle\mu\rangle$ is Q-Fuzzy left N-Subgroup of S.

Finally to show that $\langle\mu\rangle$ is the smallest Q-Fuzzy left NSubgroup containing $\mu$, let as assume that $\mathrm{Q}$ to be a Qfuzzy left $\mathrm{N}$-subgroup of $\mathrm{S}$ such that $\mu \subset \mathrm{Q}$ and show that $\langle\mu>\subset \mathrm{Q}$.

Let it possible,

$\mathrm{t}=\langle\mu>(\mathrm{x}, \mathrm{q}) \geq \mathrm{Q}(\mathrm{x}, \mathrm{q})$ for some $\mathrm{x} \in \mathrm{N}, \mathrm{q} \in \mathrm{Q}$.

Let $\in>0$ be given, then $t=\mu_{t}=\operatorname{Sup}\left\{k / x \in\left\langle\mu_{k}\right\rangle\right.$ and $\mathrm{t}-\epsilon \leq \mathrm{k} \leq \mathrm{t}$

so that $\mathrm{x} \in\left\langle\mu_{\mathrm{k}}\right\rangle \subset\left\langle\mu_{\mathrm{kt}} \in\right\rangle$, for all $\in>0$.

Now $\alpha=\alpha_{1} x_{1}+\alpha_{2} x_{2}+\alpha_{3} x_{3}+\ldots \ldots \ldots \alpha_{n} x_{n}, \alpha_{I} \in N$, $\mathrm{x}_{\mathrm{i}}$ belongs to $\mathrm{t}-\epsilon$.

$\mathrm{x}_{\mathrm{i}} \in \mu_{\mathrm{t}-\mathrm{E}}$ implies $\mu(\mathrm{xi}, \mathrm{q}) \geq \mathrm{t}-\in$,

i.e.) $\quad \mathrm{Q}(\mathrm{xi}, \mathrm{q}) \geq \mathrm{t}-\in$ for all $\in>0$

$\therefore \quad \mathrm{Q}(\mathrm{x}, \mathrm{q}) \geq \mathrm{T}\left\{\mathrm{Q}\left(\mathrm{x}_{1}, \mathrm{q}\right) \mathrm{Q}\left(\mathrm{x}_{2}, \mathrm{q}\right), \ldots \ldots \mathrm{Q}\left(\mathrm{x}_{\mathrm{n}}, \mathrm{q}\right)\right\}$

$$
\geq \quad \mathrm{t}-\in \text { for all } \in>0
$$

Hence $\mathrm{Q}(\mathrm{x}, \mathrm{q})=\mathrm{t}$ which is a contradiction to our supposition.

\section{Preposition 3.7 :}

Let ' $Q$ ' be a Q-Fuzzy left N-Subgroup near ring $\mathrm{S}$ and let $\mu+$ be a Q-Fuzzy set in $\mathrm{N}$ defined by $\mu+$ $(\mathrm{x}, \mathrm{a})=\mu(\mathrm{x}, \mathrm{a})+1-\mu(0, \mathrm{q})$ for $\mathrm{x} \in \mathrm{N}$. Then $\mu+$ is a normal Q-Fuzzy left N-subgroup of S containing ' $\mu$ '.

Proof: For any $x, y \in N$ and $q \in Q$,

We have

(i) $\mu-1(n(x-y), y)=\mu(n(x-y), q)+1-\mu(0, q)$

$\geq\{\mu(\mathrm{x}, \mathrm{q}), \mu(\mathrm{y}, \mathrm{q})\}+1-\mu(0, \mathrm{q})\}$

$\geq \mathrm{T}\{\mu(\mathrm{x}, \mathrm{q})+1-\mu(0, \mathrm{q}) \cdot \mu(\mathrm{y}, \mathrm{q})+1-(0, \mathrm{q})\}$

$=\mathrm{T}\left\{\mu^{-1}(\mathrm{x}, \mathrm{q}) \cdot \mu^{-1}(\mathrm{y}, \mathrm{q})\right\}$

(ii) $\mu+(\mathrm{nx}, \mathrm{q})=\mu(\mathrm{nx}, \mathrm{q})+1-\mu(0, \mathrm{q})$

$\geq \mu(\mathrm{x}, \mathrm{q})+1-\mu(0, \mathrm{q})$

$=\mu+(\mathrm{x}, \mathrm{q})$

\section{CONCLUSION}

OsmanKozanci, Sultanyamark and Serifeyilmaz (5) introduced the intuitconistic Q-Fuzzy R-Subgroups of near rings. In this paper we investigate the notion of Q-Fuzzy left $\mathrm{N}$-Subgroup of near ring with respect to t-norm and characterization of them.

\section{REFERENCES}

1. S.Abou.Zoid "On Fuzzy sub near rings and ideals ", Fuzzy sets and systems, 44(1991),139-146.

2. Y.U. Cho, Y.B.Jun, 'On Intuitionistic Fuzzy RSubgroup of near rings". J.Appl.Math. and Computing, 18 (1-2) (2005), 665-677.

3. K.H. Kim Y.B. Jun, “ On Fuzzy R.Subgroups of near rings”, J.Fuzzy math 8(3)(2000) 549-558.

4. K.H.Kim, Y.B. Jun, "Normal Fuzzy R-Sub groups of near rings, "J.Fuzzy Sets, Syst. 121 (2001) 341-345.

5. Osman Kazari, Sultan Yamark and Scrife Yincz, "On Intuitionistic Q-Fuzzy R Subgroups of near rings", International Mathematical Forum, 2,2007, 59 (28992910).

6. A Solai Raju and R.Nagarajan, "New Structure and Construction of Q-Fuzzy group".Advances in Fuzzy Mathematics, 4(1) (2009), 23-29.

7. L.A. Zadeh, Fuzzy Sets, inform Control, 8 (1965) 338353. 